\title{
Progress of Home-Based Food Allergy Treatment during the Coronavirus Disease Pandemic in Japan: A Cross-Sectional Multicenter Survey
}

\author{
Akihiro Maeta ${ }^{1}{ }^{\oplus}$, Yuri Takaoka ${ }^{2}$, Atsuko Nakano ${ }^{3}$, Yukiko Hiraguchi ${ }^{4}$, Masaaki Hamada ${ }^{5}{ }^{\circledR}$, Yutaka Takemura ${ }^{6}$, \\ Tomoko Kawakami ${ }^{7}$, Ikuo Okafuji ${ }^{8}$, Makoto Kameda ${ }^{2}$ and Kyoko Takahashi ${ }^{1, *}$
}

check for updates

Citation: Maeta, A.; Takaoka, Y.; Nakano, A.; Hiraguchi, Y.; Hamada, M.; Takemura, Y.; Kawakami, T.; Okafuji, I.; Kameda, M.; Takahashi, K. Progress of Home-Based Food Allergy Treatment during the Coronavirus Disease Pandemic in Japan: A Cross-Sectional Multicenter Survey. Children 2021, 8, 919. https:// doi.org/10.3390/children8100919

Academic Editor: Helen Fisher

Received: 13 September 2021

Accepted: 13 October 2021

Published: 15 October 2021

Publisher's Note: MDPI stays neutral with regard to jurisdictional claims in published maps and institutional affiliations.

Copyright: (c) 2021 by the authors. Licensee MDPI, Basel, Switzerland. This article is an open access article distributed under the terms and conditions of the Creative Commons Attribution (CC BY) license (https:// creativecommons.org/licenses/by/ $4.0 /$ )
1 Department of Food Science and Nutrition, School of Food Science and Nutrition, Mukogawa Women's University, 6-46, Ikebiraki-cho, Nishinomiya 663-8558, Japan; maeta_a@mukogawa-u.ac.jp

2 Department of Pediatrics, Osaka Prefectural Hospital Organization Osaka Habikino Medical Center, 3-7-1, Habikino 583-8588, Japan; zvb11075@nifty.com (Y.T.); kamedam@ra.opho.jp (M.K.)

3 Department of Pediatrics, Kokuho Chuo Hospital, 404-1, Miyako, Shiki 636-0302, Japan; atsuko.nah@hotmail.com

4 Department of Pediatrics, Osaka Saiseikai Nakatsu Hospital, 2-10-39, Shibata, Osaka 530-0012, Japan; hiraguchiy7240@gmail.com

5 Department of Pediatrics, Yao Municipal Hospital, 1-3-1, Ryuge-cho, Yao 581-0069, Japan; hssd1895@yahoo.co.jp

6 Department of Pediatrics, Kindai University Hospital, 377-2, Onohigashi, Osakasayama 577-8502, Japan; ytktkmr@med.kindai.ac.jp

7 Department of Pediatrics, Sumitomo Hospital, 5-3-20, Nakanoshima, Osaka 530-0005, Japan; kawakami-tomoko@sumitomo-hp.or.jp

8 Department of Pediatrics, Kobe City Hospital Organization Kobe City Medical Center General Hospital, 2-1-1, Minatoshima-cho, Kobe 650-0047, Japan; ikuoka@gmail.com

* Correspondence: taka@mukogawa-u.ac.jp; Tel.: +81-798-45-9878

Abstract: The coronavirus disease 2019 (COVID-19) pandemic's impact on food allergy treatment such as home-based oral immunotherapy (OIT) is not known. This cross-sectional, questionnairebased anonymized survey screened 2500 parents of children with allergic diseases and was conducted in the pediatric outpatient clinics of 24 hospitals. Basic clinical data of the children were collected along with the degree of allergy control, parental anxiety about emergency visits, and the risk of COVID-19 in the first state of emergency. A total of 2439 (97.6\%) questionnaires were collected, and 1315 parents who were instructed to initiate home-based OIT for their children were enrolled (OIT group). Subjective OIT progress compared to before the COVID-19 pandemic was ascertained as "Full", "Middle", "Low", "Little", and "Stop" in 264 (20.1\%), 408 (31.0\%), 384 (29.2\%), 203 (15.4\%), and 56 (4.3\%) participants, respectively. Anxiety about emergency visits and the risk of COVID-19 were negatively associated with the subjective OIT progress. In Japan, approximately half of the children continued smoothly the home-based OIT during the COVID-19 pandemic. Parents with high levels of anxiety about the disruption of the medical care system due to COVID-19 and the risk of COVID-19 did not experience a smooth continuation of home-based OIT.

Keywords: SARS-CoV-2; food allergy treatment; oral immunotherapy; COVID-19; cross-sectional studies

\section{Introduction}

Since November 2019, coronavirus disease 2019 (COVID-19) has had a profound impact on routine human life [1]. On 11 March 2020, the World Health Organization declared COVID-19 a pandemic. Several countries, such as the United States and France, implemented lockdowns with penalties to contain the COVID-19 spread. In Japan, educational institutions suspended operations on 2 March 2020 [2]. In seven Japanese cities (Tokyo, Kanagawa, Chiba, Saitama, Osaka, Hyogo, and Fukuoka), the first state of emergency 
without penalties was declared on 7 April 2020 [3]; this was extended nationwide on 16 April 2020. From 2 March 2020 to 16 April 2020, the numbers of daily and cumulative cases rose exponentially, to 4478 and 9362 cases, respectively (Supplementary Figure S1). With the goal of reducing contact between people by $70-80 \%$, the first state of emergency was implemented to prevent people from going out unnecessarily, to promote teleworking, and to request that business owners suspend operations [3]. As a result of the state of emergency, the number of people around Osaka Station was reduced by approximately $80 \%$ and $90 \%$ on weekdays and holidays, respectively, compared to the numbers before the spread of COVID-19 [4]. Moreover, the leave rates for kindergartens, elementary schools, junior high schools, and high schools were $74 \%, 95 \%, 95 \%$, and $97 \%$, respectively [5]. This state of emergency lasted approximately 1-2 months, and many people, including children, stayed at home throughout.

Oral immunotherapy (OIT) has been widely used as a novel treatment for food allergy (FA) [6]. In the Japanese Guidelines for Food Allergy 2020 [6], OIT is defined as a treatment method for cases where the early acquisition of tolerance during the natural course cannot be anticipated. After a symptom induction threshold has been determined during an earlier oral food challenge, causative foods are taken under a physician's instruction, aiming to acquire the conditions of increased threshold or desensitization [6]. In Japan, the number of patients receiving OIT increased approximately sixfold from 2012 to 2015 [6]. OITs are continued at home [6-8], despite the ingestion of food antigens posing a risk of adverse reaction. Therefore, in home-based OIT, it is essential to prescribe therapeutic drugs, including adrenaline and antihistaminic medicines and to expand safety measures such as 24-h emergency consultation and cooperation with local emergency medical institutions. The continuation of OIT greatly affects not only the patient but also the parents' willingness to treat their children. Anxiety about dealing with allergic reactions and about a 24-h emergency consultation system is related to psychological burdens for parents [9]. In an anonymous and voluntary online cross-sectional survey in Australia, it was reported that COVID-19 pandemic made it difficult to access new food experiences and FA-related health services [10]. Thus, it was considered that the spread of COVID-19 is one of factors preventing the smooth continuation of OIT given the increase in psychological burden on parents.

The relationship between the COVID-19 pandemic and FA treatments has been explored previously [10-18], although these reports were review articles (not surveys) [11-17] or small-scale surveys that included patients and their parents $[10,18,19]$. However, no large-scale study comprising more than 1000 subjects has evaluated the relationship between the COVID-19 pandemic and FA treatment. We hypothesized that the food antigen exposure process would be disrupted by the COVID-19 pandemic. Therefore, we aimed to explore the subjective progression of home-based OIT by the COVID-19 pandemic on the perspective of the parent's psychological state.

\section{Materials and Methods}

\subsection{Facilities, Subjects, and Ethical Considerations}

This cross-sectional, anonymized survey was conducted in the pediatric outpatient clinics of 24 hospitals in Osaka, Hyogo, and Nara from October 2020 to April 2021 (Supplementary Table S1) with the approval of each hospital and the Research Ethics Committee of Mukogawa Women's University (approval number: 20-65). The parents/guardians of the children with allergic diseases were fully informed about the survey verbally and in writing. The submission of a questionnaire was considered to be consent in the survey. The participants were 2500 parents continually going to the pediatric outpatient clinics of 24 hospitals to treat their children (aged 0-15 years) with allergic diseases. In this survey, we defined OIT as a FA treatment that involves ingesting the causative food at home to increase the threshold of food allergen. 


\subsection{Questionnaire}

The original contents of the questionnaire were designed by pediatricians, and survey responses were anonymized (Supplementary Figures S2 and S3). The questionnaire assessed the following: two questions about FA treatment for children (FQ1 and FQ2); four questions about the parents' anxiety about visiting the hospital, ambulatory care, and the risk of severe acute respiratory syndrome coronavirus 2 (SARS-CoV-2) infection in the first state of emergency (Q1-Q4); the Japanese-translated State-Trait Anxiety Inventory (STAI) [20]; and basic clinical and epidemiological information of the children with allergic diseases.

The influence on FA treatments of the COVID-19 pandemic (FQ2) was determined by the subjective evaluation of parents on the progress of home-based OIT during the spread. The FQ2 asked parents who had children carrying out OIT at home for the comparison to before the spread of COVID-19. The subjective progress of home-based OIT was rated with five options: "Full progress as planned" (Full), "Middle progress not as planned" (Middle), "Low progress not as planned" (Low), "Little progress" (Little), and "Stop of the treatment" (Stop) were included. Moreover, we investigated the reasons for progress and non-progress using a free-text descriptive formula.

For answers to questions about the parents' anxiety (Q1-Q4) regarding emergency visits, ambulatory care, and SARS-CoV-2 infection, the options were: "None", "Not really", "Some", "A lot", and "Quite a lot".

Anxietas (anxiety as a personality trait) was measured using the STAI [20].

\subsection{Inclusion/Exclusion Criteria}

Inclusion criteria of the OIT group is a "Yes" answer to FQ1. The flow chart of the selection of analyzed questionnaires is shown in Figure 1. Exclusion criteria for the final analysis was parents with children who do not have FA, parents with children who do not carry out home-based OIT (FQ1), and parents who did not answer FQ1 and FQ2.

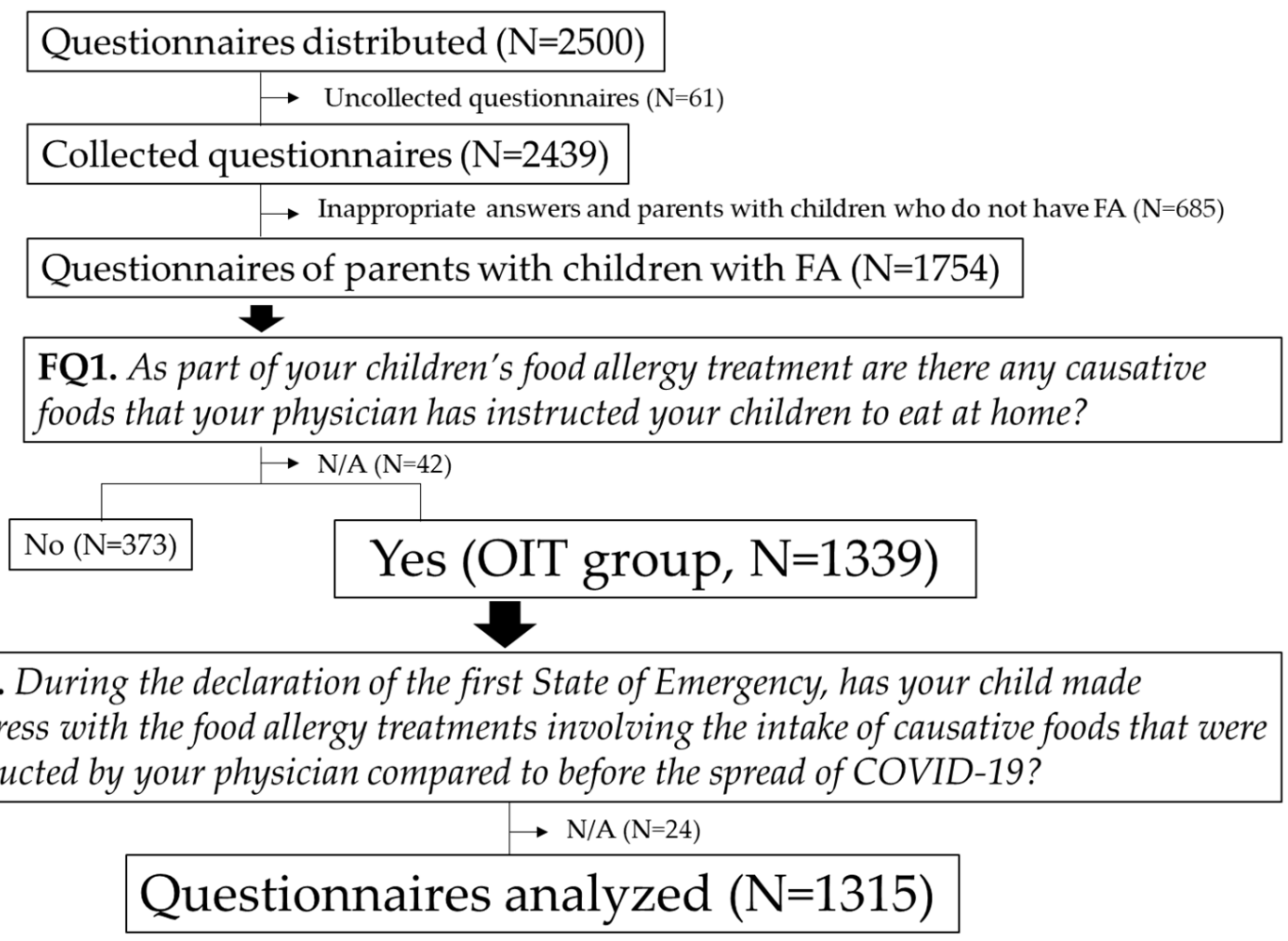

Figure 1. Flowchart of the participant selection process employed in this study. 


\subsection{Statistical analyses}

Children's ages and the STAI of the parents are presented as medians and interquartile ranges. All other data are presented as numbers and percentages.

In the stratified analysis of the parents' anxiety (Q1-Q4), we included "None" and "Not really" in the low-anxiety (small) group; "Some" in the medium-anxiety (medium) group; and "A lot" and "Quite a lot" in the high-anxiety (large) group.

In males and females, an anxiety score of more than 44 or 45 points, respectively, was indicative of high anxietas [20].

Statistical analyses were conducted using the chi-square test. The family-wise error rate was corrected using Bonferroni's method. Differences were considered significant at $p<0.05$. All analyses were conducted using GraphPad Prism (version 5.0; La Jolla, CA, USA).

\section{Results}

\subsection{Participant Information and Subjective Progress of Home-Based OIT}

A flowchart of the participant selection process is shown in Figure 1.

A total of 2439 questionnaires were collected (response rate: 97.6\%). Among these, we excluded the questionnaires of parents who did not have children with FA, which left 1754 completed questionnaires from parents of children with FA. Of these, 1339 questionnaires were from parents who were instructed to conduct home-based OIT for their children (OIT group). The final analysis included 1315 questionnaires, after excluding 24 questionnaires that did not include answers to the question about the progress of causative food intake (FQ2). The baseline information of the children with FA and their parents is shown in Table 1.

Table 1. Background information of parents and children.

\begin{tabular}{|c|c|}
\hline Item & $\begin{array}{c}\text { Number (\%) or } \\
\text { Median (25th-75th Percentile) }{ }^{1}\end{array}$ \\
\hline Parents & 1315 \\
\hline \multicolumn{2}{|l|}{ Relationship } \\
\hline Father & $90(6.8 \%)$ \\
\hline Mother & $1216(92.5 \%)$ \\
\hline Other or no answer (N/A) & $9(0.7 \%)$ \\
\hline \multicolumn{2}{|l|}{ STAI of parents $(\mathrm{N}=1230)$} \\
\hline Total score & $91(80-105)$ \\
\hline Angor (anxiety as a now state) & $46(40-54)$ \\
\hline Anxietas (anxiety as a personality trait) & $44(38-53)$ \\
\hline Children with FA & 1429 \\
\hline Age, year $(\mathrm{N}=1414)$ & $6(3-9)$ \\
\hline \multicolumn{2}{|l|}{ Sex } \\
\hline Boys & $942(65.9 \%)$ \\
\hline Girls & $481(33.7 \%)$ \\
\hline $\mathrm{N} / \mathrm{A}$ & $8(0.6 \%)$ \\
\hline \multicolumn{2}{|c|}{ Prevalence of allergic diseases other than FA (multiple answers allowed) } \\
\hline Bronchial asthma & $279(19.5 \%)$ \\
\hline Atopic dermatitis & $580(40.6 \%)$ \\
\hline Allergic rhinitis & $315(22.0 \%)$ \\
\hline Allergic conjunctivitis & $63(4.4 \%)$ \\
\hline History of anaphylaxis & $247(17.3 \%)$ \\
\hline Prescription of adrenaline & $570(39.9 \%)$ \\
\hline \multicolumn{2}{|c|}{ Oral immunotherapy food (multiple answers allowed) } \\
\hline Hen's egg & $834(58.4 \%)$ \\
\hline Cow's milk & $481(33.7 \%)$ \\
\hline Wheat & $218(15.3 \%)$ \\
\hline Other (such as peanuts, soybean and etc.) & $56(4.0 \%)$ \\
\hline
\end{tabular}

${ }^{1}$ Data on age of children and State-Trait Anxiety Inventory (STAI) of parents are presented as median and interquartile range. All other data are shown as number and percentage. N/A; No answer. 
Compared to before the COVID-19 pandemic, the question about the subjective progress of home-based OIT (FQ2) elicited the following responses: "Full" in 264 (20.1\%) respondents, "Middle" in 408 (31.0\%), "Low" in 384 (29.2\%), "Little" in 203 (15.4\%), and "Stop" in 56 (4.3\%) (Figure 2). The analysis of the free-text descriptive responses of the reasons for "Full" or "Middle" showed that the frequency of the appearance of "at home", "time", and "increased" was high, but the reasons for "Low", "Little", or "Stop" showed that the frequency of "emergency", "consultation", "scary", and "symptom" was high (data not shown for both).

\section{OIT progress during the first state of emergency compared to before the spread of COVID-19}

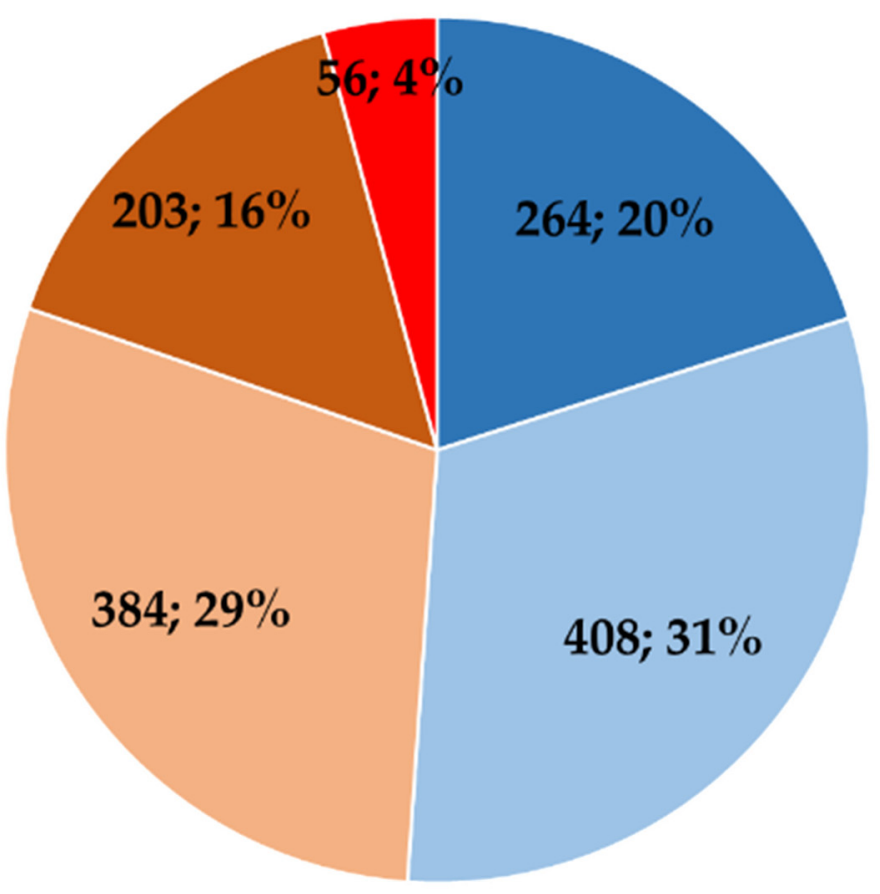

- (1) Full progress as planned (Full)

(3) Low progress not as planned (Low)

(5) Stop of the treatment (Stop)
(2) Middle progress not as planned (Middle)

- (4) Little progress (Little)

Figure 2. Progress of home-based oral immunotherapy (OIT) in the first state of emergency. Data are shown as the number of respondents and percentage (parents).

3.2. Relationship between the Participant's Information and the Subjective Progress of Home-Based OIT

Stratified analyses showed no associations between the subjective progress of homebased OIT and age of the child, the prevalence of allergic diseases other than FA, the history of anaphylaxis, and the location of the outpatient hospitals; however, there was a significant association between the prescription of adrenaline and the progress of homebased treatment (Table 2). The percentage of respondents who answered "Full", "Little", and "Stop" for the OIT progress question was higher in those who had a prescription for adrenaline than in those who did not have a prescription (Table 2). 
Table 2. Relationship between the subject's information and the oral immunotherapy (OIT) progress during the first state of emergency.

\begin{tabular}{|c|c|c|c|c|c|c|c|}
\hline & & \multicolumn{5}{|c|}{ OIT Progress Compared to before the Spread of COVID-19 } & \multirow{2}{*}{$\begin{array}{l}p \text {-Value } \\
\left(\chi^{2} \text {-Test }\right)\end{array}$} \\
\hline & & Full & Middle & Low & Little & Stop & \\
\hline \multicolumn{8}{|c|}{ Have at least child with FA over 6 years old } \\
\hline Yes & $\mathrm{N}=693$ & $138(19.9 \%)$ & $195(28.1 \%)$ & $211(30.4 \%)$ & $115(16.6 \%)$ & $34(4.9 \%)$ & \multirow{3}{*}{0.094} \\
\hline No & $\mathrm{N}=609$ & $123(20.2 \%)$ & $210(34.5 \%)$ & $169(27.8 \%)$ & $86(14.1 \%)$ & $21(3.4 \%)$ & \\
\hline $\mathrm{N} / \mathrm{A}$ & $\mathrm{N}=13$ & & & & & & \\
\hline \multicolumn{8}{|c|}{ Prevalence of allergic diseases other than FA } \\
\hline Only FA & $\mathrm{N}=600$ & $132(22.0 \%)$ & $195(32.5 \%)$ & $167(27.8 \%)$ & $85(14.2 \%)$ & $21(3.5 \%)$ & \multirow{2}{*}{0.188} \\
\hline $\begin{array}{c}\text { Other } \\
\text { diseases }\end{array}$ & $\mathrm{N}=715$ & $132(18.5 \%)$ & $213(29.8 \%)$ & $217(30.3 \%)$ & $118(16.5 \%)$ & $35(4.9 \%)$ & \\
\hline \multicolumn{8}{|c|}{ History of anaphylaxis } \\
\hline Yes & $\mathrm{N}=233$ & $45(19.3 \%)$ & $61(26.2 \%)$ & $70(30.0 \%)$ & $40(17.2 \%)$ & $17(7.3 \%)$ & \multirow{2}{*}{0.062} \\
\hline No & $N=1082$ & $219(20.2 \%)$ & $347(32.1 \%)$ & $314(29.0 \%)$ & $163(15.1 \%)$ & $39(3.6 \%)$ & \\
\hline \multicolumn{8}{|c|}{ Prescription of adrenaline } \\
\hline Yes & $\mathrm{N}=549$ & $122(22.2 \%)$ & $146(26.6 \%)$ & $153(27.9 \%)$ & $98(17.9 \%)$ & $30(5.5 \%)$ & \multirow{2}{*}{0.004} \\
\hline No & $\mathrm{N}=766$ & $142(18.5 \%)$ & $262(34.2 \%)$ & $231(30.2 \%)$ & $105(13.7 \%)$ & $26(3.4 \%)$ & \\
\hline \multicolumn{8}{|c|}{ Location of outpatient hospital } \\
\hline Osaka & $\mathrm{N}=974$ & $207(21.3 \%)$ & $297(30.5 \%)$ & $283(29.1 \%)$ & $145(14.9 \%)$ & $42(4.3 \%)$ & \multirow{3}{*}{0.734} \\
\hline Hyogo & $\mathrm{N}=132$ & $24(18.2 \%)$ & $41(31.1 \%)$ & $42(31.8 \%)$ & $21(15.9 \%)$ & $4(3.0 \%)$ & \\
\hline Nara & $\mathrm{N}=209$ & $33(15.8 \%)$ & $70(33.5 \%)$ & $59(28.2 \%)$ & $37(17.7 \%)$ & $10(4.8 \%)$ & \\
\hline
\end{tabular}

Data $(\mathrm{N}=1315)$ are presented as the number and the percentage of respondents (parents) in each group. N/A; No answer.

3.3. Relationship between Parents' Anxiety about Emergency Visits, Ambulatory Care, and SARS-CoV-2 Infections and the Subjective Progress of Home-Based OIT

For all questions (Table 3), parents in the low- and medium-anxiety groups had more "Full" and "Middle" progress compared with those in the high-anxiety group. In Q1 and Q3 (questions about emergency or outpatient treatment), the proportion of respondents who answered "Low", "Little", and "Stop" in the high-anxiety group was higher than those in the low- and medium-anxiety groups (Table 3). In Q2 and Q4 (questions related to anxieties about COVID-19), the proportion of respondents who answered "Low", "Little", and "Stop" was higher in the high-anxiety group than those in the low- and medium-anxiety groups (Table 3). Moreover, in Q2 and Q4, the most common answer in the low-anxiety group was "Middle", while "Low" was the most common answer in the medium-anxiety group (Table 3). 
Table 3. Relationship between the subject's information and the oral immunotherapy (OIT) progress during the first state of emergency.

\begin{tabular}{|c|c|c|c|c|c|c|c|c|}
\hline & & \multicolumn{5}{|c|}{ OIT Progress Compared to before the Spread of COVID-19 } & \multirow{2}{*}{\multicolumn{2}{|c|}{$\begin{array}{l}p \text {-Value } \\
\left(\chi^{2} \text {-Test }\right)\end{array}$}} \\
\hline & & Full & Middle & Low & Little & Stop & & \\
\hline \multicolumn{9}{|c|}{ Q1. Did you experience any anxiety as to whether you would be able to have normal consultations at the hospital (outpatient or emergency)? } \\
\hline $\begin{array}{l}\text { Low anxiety } \\
\text { "None" or "Not really" }\end{array}$ & $\mathrm{N}=153$ & $\begin{array}{c}50 \\
(32.7 \%)\end{array}$ & $\begin{array}{c}46 \\
(30.1 \%)\end{array}$ & $\begin{array}{c}36 \\
(23.5 \%)\end{array}$ & $\begin{array}{c}16 \\
(10.5 \%)\end{array}$ & $\begin{array}{c}5 \\
(3.3 \%)\end{array}$ & Small vs. Medium & 0.116 \\
\hline $\begin{array}{l}\text { Medium anxiety } \\
\text { "Some" }\end{array}$ & $\mathrm{N}=450$ & $\begin{array}{c}98 \\
(21.8 \%)\end{array}$ & $\begin{array}{c}152 \\
(33.8 \%)\end{array}$ & $\begin{array}{c}127 \\
(28.2 \%)\end{array}$ & $\begin{array}{c}66 \\
(14.7 \%)\end{array}$ & $\begin{array}{c}7 \\
(1.6 \%)\end{array}$ & Small vs. Large & $<0.001$ \\
\hline $\begin{array}{c}\text { High anxiety } \\
\text { "A lot" or "Quite a lot" }\end{array}$ & $\mathrm{N}=709$ & $\begin{array}{c}116 \\
(16.4 \%)\end{array}$ & $\begin{array}{c}209 \\
(29.5 \%)\end{array}$ & $\begin{array}{c}220 \\
(31.0 \%)\end{array}$ & $\begin{array}{c}120 \\
(16.9 \%)\end{array}$ & $\begin{array}{c}44 \\
(6.2 \%)\end{array}$ & Medium vs. Large & $<0.001$ \\
\hline $\mathrm{N} / \mathrm{A}$ & $\mathrm{N}=3$ & & & & & & & \\
\hline \multicolumn{9}{|c|}{ Q2. Did you worry that by going to the hospital, your family could become infected with COVID-19? } \\
\hline $\begin{array}{l}\text { Low anxiety } \\
\text { "None" or "Not really" }\end{array}$ & $\mathrm{N}=153$ & $\begin{array}{c}46 \\
(30.1 \%)\end{array}$ & $\begin{array}{c}57 \\
(37.3 \%)\end{array}$ & $\begin{array}{c}28 \\
(18.3 \%)\end{array}$ & $\begin{array}{c}20 \\
(13.1 \%)\end{array}$ & $\begin{array}{c}2 \\
(1.3 \%)\end{array}$ & Small vs. Medium & 0.018 \\
\hline $\begin{array}{l}\text { Medium anxiety } \\
\text { "Some" }\end{array}$ & $\mathrm{N}=422$ & $\begin{array}{c}90 \\
(21.3 \%)\end{array}$ & $\begin{array}{c}131 \\
(31.0 \%)\end{array}$ & $\begin{array}{c}142 \\
(33.6 \%)\end{array}$ & $\begin{array}{c}50 \\
(11.8 \%)\end{array}$ & $\begin{array}{c}9 \\
(2.1 \%)\end{array}$ & Small vs. Large & $<0.001$ \\
\hline $\begin{array}{c}\text { High anxiety } \\
\text { "A lot" or "Quite a lot" }\end{array}$ & $\mathrm{N}=738$ & $\begin{array}{c}128 \\
(17.3 \%)\end{array}$ & $\begin{array}{c}219 \\
(29.7 \%)\end{array}$ & $\begin{array}{c}214 \\
(29.0 \%)\end{array}$ & $\begin{array}{c}132 \\
(17.9 \%)\end{array}$ & $\begin{array}{c}45 \\
(6.1 \%)\end{array}$ & Medium vs. Large & 0.002 \\
\hline $\mathrm{N} / \mathrm{A}$ & $\mathrm{N}=2$ & & & & & & & \\
\hline \multicolumn{9}{|c|}{ Q3. Have you ever worried about the opinions of others and thought about postponing or cancelling a scheduled outpatient appointment/test/inpatient treatment? } \\
\hline $\begin{array}{c}\text { Low anxiety } \\
\text { "None" or "Not really" }\end{array}$ & $\mathrm{N}=597$ & $\begin{array}{c}148 \\
(24.8 \%)\end{array}$ & $\begin{array}{c}200 \\
(33.5 \%)\end{array}$ & $\begin{array}{c}149 \\
(25.0 \%)\end{array}$ & $\begin{array}{c}81 \\
(13.6 \%)\end{array}$ & $\begin{array}{c}19 \\
(3.2 \%)\end{array}$ & Small vs. Medium & 0.461 \\
\hline $\begin{array}{c}\text { Medium anxiety } \\
\text { "Some" }\end{array}$ & $\mathrm{N}=349$ & $\begin{array}{c}63 \\
(18.1 \%)\end{array}$ & $\begin{array}{c}124 \\
(35.5 \%)\end{array}$ & $\begin{array}{c}104 \\
(29.8 \%)\end{array}$ & $\begin{array}{c}47 \\
(13.5 \%)\end{array}$ & $\begin{array}{c}11 \\
(3.2 \%)\end{array}$ & Small vs. Large & $<0.001$ \\
\hline $\begin{array}{c}\text { High anxiety } \\
\text { "A lot" or "Quite a lot" }\end{array}$ & $\mathrm{N}=367$ & $\begin{array}{c}53 \\
(14.4 \%)\end{array}$ & $\begin{array}{c}83 \\
(22.6 \%)\end{array}$ & $\begin{array}{c}131 \\
(35.7 \%)\end{array}$ & $\begin{array}{c}74 \\
(20.2 \%)\end{array}$ & $\begin{array}{c}26 \\
(7.1 \%)\end{array}$ & Medium vs. Large & $<0.001$ \\
\hline N/A & $\mathrm{N}=2$ & & & & & & & \\
\hline \multicolumn{9}{|c|}{ Q4. Have you ever experienced anxiety that, due to allergies, a COVID-19 infection could become worse? } \\
\hline $\begin{array}{c}\text { Low anxiety } \\
\text { "None" or "Not really" }\end{array}$ & $\mathrm{N}=647$ & $\begin{array}{c}145 \\
(22.4 \%)\end{array}$ & $\begin{array}{c}229 \\
(35.4 \%)\end{array}$ & $\begin{array}{c}172 \\
(26.6 \%)\end{array}$ & $\begin{array}{c}86 \\
(13.3 \%)\end{array}$ & $\begin{array}{c}15 \\
(2.3 \%)\end{array}$ & Small vs. Medium & 0.036 \\
\hline $\begin{array}{c}\text { Medium anxiety } \\
\text { "Some" }\end{array}$ & $\mathrm{N}=287$ & $\begin{array}{c}48 \\
(16.7 \%)\end{array}$ & $\begin{array}{c}82 \\
(28.6 \%)\end{array}$ & $\begin{array}{c}102 \\
(35.5 \%)\end{array}$ & $\begin{array}{c}47 \\
(16.4 \%)\end{array}$ & $\begin{array}{c}8 \\
(2.8 \%)\end{array}$ & Small vs. Large & $<0.001$ \\
\hline $\begin{array}{c}\text { High anxiety } \\
\text { "A lot" or "Quite a lot" }\end{array}$ & $\mathrm{N}=379$ & $\begin{array}{c}71 \\
(18.7 \%)\end{array}$ & $\begin{array}{c}96 \\
(25.3 \%)\end{array}$ & $\begin{array}{c}110 \\
(29.0 \%)\end{array}$ & $\begin{array}{c}69 \\
(18.2 \%)\end{array}$ & $\begin{array}{c}33 \\
(8.7 \%)\end{array}$ & Medium vs. Large & 0.037 \\
\hline $\mathrm{N} / \mathrm{A}$ & $\mathrm{N}=2$ & & & & & & & \\
\hline
\end{tabular}


3.4. Relationship between Parents' Anxietas (Anxiety as a Personality Trait) and the Subjective Progress of Home-Based OIT

The STAI had 1230 (93.5\%) and 85 (6.5\%) complete and incomplete answers, respectively. The proportion of respondents with high anxietas comprised approximately half of the study population $(49.9 \%, 614 / 1230)$. There was no association between the anxietas groups of parents and the subjective progression of home-based OIT (Figure 3).

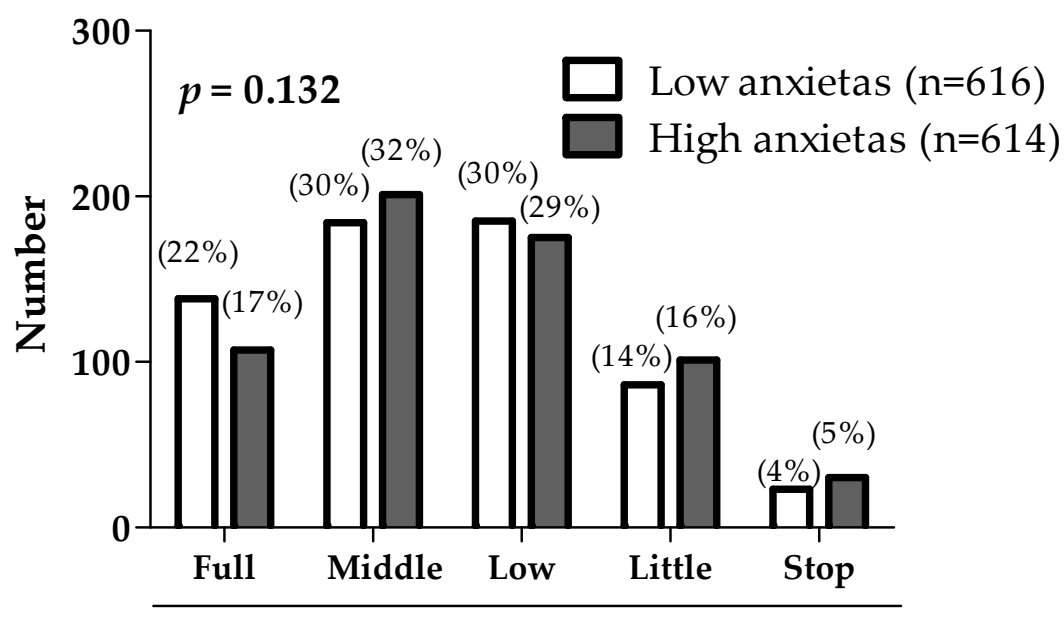

OIT progress compared to before the spread of COVID-19

Figure 3. Relationship between anxietas (anxiety as a personality trait) of parents and the progress of home-based oral immunotherapy (OIT). Data are shown as the number of respondents and percentage (parents).

\section{Discussion}

The COVID-19 pandemic has profoundly impacted daily life worldwide [1]. In Japan, the state of emergency without penalties was first declared in April 2020 [3]. However, with the COVID-19 pandemic disrupting medical practice and the restriction of outings under the state of emergency, it was unclear how parents managed home-based OIT for their children. Therefore, we aimed to explore the subjective progression of home-based OIT by the COVID-19 pandemic on the perspective of the parent's psychological state.

The home-based OIT requires ingestion of the causative food antigen at home. However, the ingestion of food allergenic products for OIT poses the risk of an adverse reaction [6]. Ozturk et al. reported that only $21 \%$ of the respondents were continuing subcutaneous immunotherapy as usual during the COVID-19 pandemic [18]. Krishna et al. reported that there was a highly significant decrease in subcutaneous immunotherapy up dosing and maintenance during the pandemic [19]. We predicted that many parents would temporarily suspend the home-based OIT for children with FA to avoid the risk of emergency visits and ambulatory care for adverse reactions. However, the rate of discontinuation of OIT ("Stop") was less than 5\%, even in the first state of emergency. Moreover, approximately half of the patients were able to make complete or partial progress with home-based OIT compared to that before the COVID-19 pandemic. From the analysis of the free-text descriptions, the reason for the smooth continuation of home-based OIT was most likely due to the increased time spent at home. After children with FA ingest the food antigen, parents need to monitor the condition of their children due to the likelihood of an induced allergic reaction [6]. Papadopoulos et al. reported that outcomes in pediatric asthma may even have improved by increased adherence and/or reduced exposure during the COVID-19 pandemic [21]. Therefore, we considered the possibility that the increased time spent at home due to the state of emergency contributed to the increased observation time after the children with FA had ingested the food antigen. This was the reason for the smooth continuation of OIT. 
However, approximately half of the patients ("Low", "Little", and "Stop") were unable to continue smoothly the home-based OIT or had to discontinue it. We explored factors that were related to the OIT progress and found a significant association between the prescription of adrenaline and the ability to progress in home-based OIT. The parents of children with FA who were prescribed adrenaline tended to have more difficulties continuing the home-based OIT. Adrenaline is prescribed to children with severe FA. Therefore, we considered it likely that the parents decided not to proceed with OIT to avoid the risk of serious allergic reactions at home. Chen et al. and Tagami et al. reported that the number of children with an immediate allergic reaction to foods decreased during COVID19 pandemic $[10,22]$. From the stratified analysis and analysis of free-text descriptions, parents who experienced strong anxiety against ambulatory visits, emergency care, and risk of SARS-CoV-2 infection tended to be less able to continue smoothly the home-based OIT. However, there was no association between a parent's anxiety as a personality trait and the OIT progress. Parents of children with severe FA, who are at a high risk of requiring emergency care after consuming the causative antigen, may have been more sensitive to the disruption of the medical care system.

Furthermore, we found an interesting association between the prescription of adrenaline and the subjective progress of home-based OIT. A higher proportion of the group of parents of children who were prescribed adrenaline answered "Full" to the question about the progress of home-based OIT than those of children who were not prescribed adrenaline. Injectable adrenaline is an essential emergency treatment that parents can administer if an anaphylactic shock occurs following the intake of causative food antigens [6]. Thus, we inferred that the prescription of adrenaline gave parents a sense of relief. Parents with low anxiety about the confusing medical care systems and risks of SARS-CoV-2 infection tended to experience the smooth continuation of home-based OIT. For OIT progression, it is important to dispel excessive anxiety about the COVID-19 pandemic in the parents and teach them to administer emergency treatments for severe FA-treatment-related adverse symptoms. Therefore, to ensure the smooth continuation of home-based OIT during a pandemic, it may be important for physicians to address parental anxieties regarding OIT by providing accurate information about COVID-19, the availability of hospital services, and by prescribing essential medicines.

This study has some limitations. First, this study has selection bias because the participants of this survey were the parents of children who continued to seek consultation for the treatment of allergic diseases. Parents who did not continue to seek consultation for their children following the onset of the COVID-19 pandemic were not included. Thus, the number of discontinuations of OIT may be higher than the results of this survey. Second, this survey was conducted only in Japan. From March to May 2020, the cumulative number of SARS-CoV-2 infections was lower in Japan than in other developed countries, such as the United States and European countries. Therefore, it is possible that the impact of the COVID-19 pandemic was smaller in Japan than in other developed countries. Third, the possibility of recall bias exists as the parents' memories may have affected their answers. Fourth, we did not clearly define the progression of OIT because OIT methods with food antigen ingestion vary from facility to facility and from patient to patient. However, FQ2 (the subjective progression of home-based OIT) asked the parents who had children carrying out OIT at home for the comparison of conditions before the spread of COVID-19. Therefore, we considered that FQ2 (the subjective progression of home-based OIT) could evaluate relative progress in in the subjectivity of parents compared to before the spread of COVID-19. Fifth, because the survey was anonymous, the patient's medical records and the completed questionnaire could not be linked. The information provided by parents may not match the child's correct diagnosis record. However, we considered that most children with FA in this study were diagnosed by an oral food challenge test because the determination of their intake threshold to allergen foods is needed to conduct home-based OIT. 


\section{Conclusions}

In Japan, home-based OIT was continued during the COVID-19 pandemic, and half of parents were able to comply with OIT for their children. Parents with high anxiety about the disruption of medical care systems were more likely to discontinue home-based OIT. Furthermore, preventing pandemics is essential for the management of diseases other than infectious diseases.

Supplementary Materials: The following are available online at https: / www.mdpi.com/article/ 10.3390/children8100919/s1, Table S1: Surveyed Hospitals; Figure S1: The number of individuals infected with the severe acute respiratory syndrome coronavirus 2 in Japan from 24 February to 1 June 2020; Figure S2: Questionnaire assessing progress of food allergy treatment (FQ1 and 2) and parents' anxiety about visiting hospital, ambulatory care, and SARS-CoV-2 infection (Q1-Q4) in the first state of emergency; Figure S3: Questionnaire assessing the child's epidemiological and clinical information.

Author Contributions: Conceptualization, A.M., Y.T. (Yuri Takaoka), A.N., M.K., and K.T.; methodology, A.M, Y.T. (Yuri Takaoka), A.N., Y.H., M.H., Y.T. (Yutaka Takemura), T.K., I.O., M.K., and K.T.; validation, Y.T. (Yuri Takaoka), A.N., Y.H., M.H., Y.T. (Yutaka Takemura), T.K., I.O., and M.K.; formal analysis, A.M., Y.T. (Yuri Takaoka), and A.N.; investigation, Y.T. (Yuri Takaoka), A.N., Y.H., M.H., Y.T. (Yutaka Takemura), T.K., I.O., and M.K.; resources, K.T.; data curation, A.M., Y.T. (Yuri Takaoka), and A.N.; writing—original draft preparation, A.M.; writing—review and editing, Y.T. (Yuri Takaoka), A.N., M.K., and K.T.; visualization, A.M.; supervision, M.K. and K.T.; funding acquisition, A.M., A.N., and M.K. All authors have read and agreed to the published version of the manuscript.

Funding: This study was a part of the project "Measurement of psychological burden by food allergy immunotherapy and the relationship between stress and therapeutic effect" (principal investigator: Akihiro Maeta), which was supported by a Grant-in-Aid for Young Scientists (Grant Number: 19K14042) from the Japan Society for the Promotion of Science.

Institutional Review Board Statement: This study was conducted according to the guidelines of the Declaration of Helsinki, and approved by the Ethics Committees of the 24 included hospitals and Mukogawa Women's University (approval number: 20-65, 18 November 2020).

Informed Consent Statement: Informed consent was obtained from all subjects involved in the study. The submission of a questionnaire was considered to be consent in the survey.

Acknowledgments: We extend our sincerest gratitude to the guardians of the children with allergic diseases who participated in this study. Additionally, we are grateful to Izumoto Kozue, who entered the free-description data, and to all in the pediatric departments who recruited study participants (Appendix A).

Conflicts of Interest: The authors have no conflicts of interest to declare.

\section{Appendix A. List of Primary Investigators and Co-Investigators}

Primary Investigators

Akagawa Shohei MD, PhD ${ }^{1}$, Anzai Kaori, MD ${ }^{2}$, Bandou Kenji, MD ${ }^{3}$, Ikeda Akiko, MD ${ }^{4}$, Doi Masaaki, MD, PhD ${ }^{5}$, Enomoto Masahiro, $\mathrm{MD}, \mathrm{PhD}^{6}$, Fujikawa Shiori, $\mathrm{MD}^{7}$, Nagai Megumi MD, $\mathrm{PhD}^{8}$, Nishiyama Atsuko, MD ${ }^{9}$, Otsuka Keita, MD ${ }^{10}$, Shimizu Satoko, MD 11,12, Sugimoto Yukiko, MD ${ }^{13}$, Sumimoto Shinichi, MD, PhD ${ }^{2}$, Tanaka Yukiko, MD ${ }^{14}$, Tanaka Yuko, MD ${ }^{15}$, Tanaka Yuya, MD ${ }^{16}$, Wakahara Ryohei, MD, PhD ${ }^{17}$, Yamasaki Koji, MD, PhD ${ }^{18}$

Co-Investigators

Arima Tomoyuki, MD ${ }^{8}$, Imaide Aya, MD ${ }^{6}$, Fukasawa Yohei, MD ${ }^{21}$, Hashimoto Naoki, $\mathrm{MD}^{19}$, Masumi Hiroki MD ${ }^{8}$, Matsutani Eri, $\mathrm{MD}^{3}$, Kim Jong Soo, MD ${ }^{20}$, Nakai Yoko, MD ${ }^{1}$, Nakamichi Erina, MD ${ }^{2}$, Natsuki Momo MD ${ }^{16}$, Onaka Masayuki, MD ${ }^{9}$, Shingaki Tomoya, MD ${ }^{20}$, Sunaga Ayana, MD ${ }^{3}$, Tsurinaga Yuki, MD ${ }^{21}$, Yamada Saki, MD ${ }^{20}$, Yamagishi Mitsuru, $\mathrm{MD}^{1}$

${ }^{1}$ Kansai Medical University Hospital 


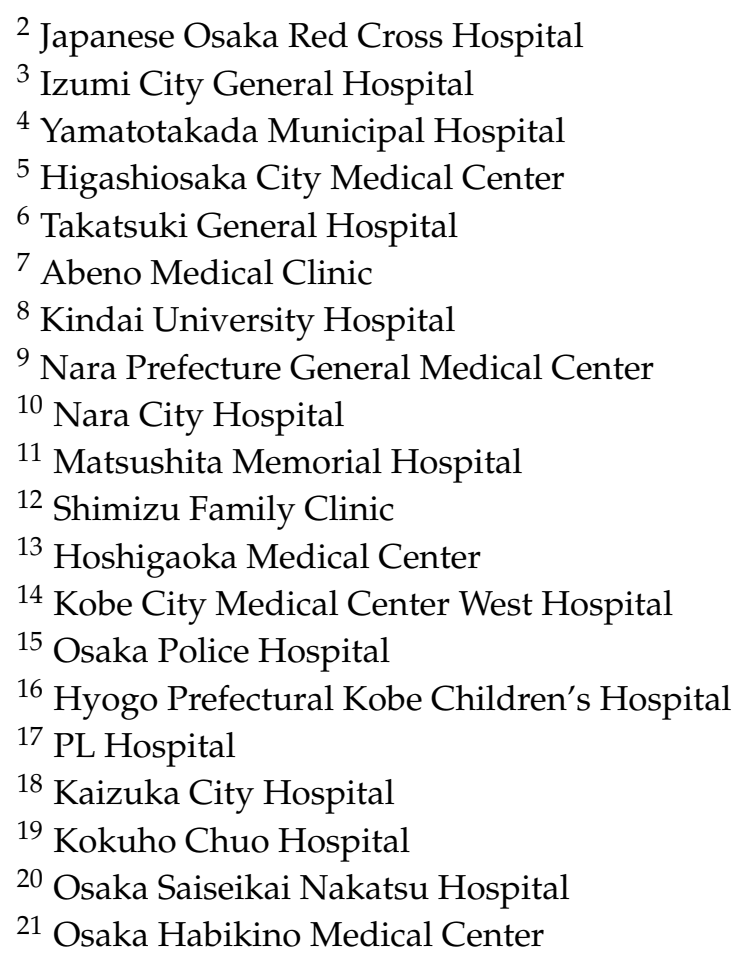

\section{References}

1. WHO. Coronavirus Disease (COVID-19) Dashboard. Available online: https:/ / covid19.who.int/ (accessed on 8 September 2021).

2. 16th COVID-19 Control Headquarters. Available online: https://www.kantei.go.jp/jp/98_abe/actions/202003/01corona.html (accessed on 8 September 2021).

3. Prime Minister Abe Press Conference on New Coronavirus Infection. Available online: https://www.kantei.go.jp/jp/98_abe/ statement/2020/0407kaiken.html (accessed on 8 September 2021).

4. How Many People Are There in the City? Japanese 18 Points Graph. Available online: https://www3.nhk.or.jp/news/special/ coronavirus/outflow-data/ (accessed on 8 September 2021).

5. Implementation Status of Temporary Closure at Schools for Measures Against New Coronavirus Infectious Diseases. Available online: https://www.mext.go.jp/content/20200424-mxt_kouhou01-000006590_1.pdf (accessed on 8 September 2021).

6. Ebisawa, M.; Ito, K.; Fujisawa, T. Japanese guidelines for food allergy 2020. Allergol. Int. 2020, 69, 370-386. [CrossRef] [PubMed]

7. Takaoka, Y.; Maeta, A.; Takahashi, K.; Ito, Y.M.; Takahashi, S.; Muroya, T.; Shigekawa, A.; Tsurinaga, Y.; Iba, N.; Yoshida, Y.; et al. Effectiveness and safety of double-blind, placebo-controlled, low-dose oral immunotherapy with low allergen egg-containing cookies for severe hen's egg allergy: A single-center analysis. Int. Arch. Allergy Immunol. 2019, 180, 244-249. [CrossRef] [PubMed]

8. Sugiura, S.; Kitamura, K.; Makino, A.; Matsui, T.; Furuta, T.; Takasato, Y.; Kando, N.; Ito, K. Slow low-dose oral immunotherapy: Threshold and immunological change. Allergol. Int. 2020, 69, 601-609. [CrossRef] [PubMed]

9. Maeta, A.; Takaoka, Y.; Kameda, M.; Takahashi, K. Development of a Therapy-related Psychological Burden Scale for Parents with Children Undergoing Oral Immunotherapy for Food Allergy. J. Child. Health 2020, 79, 55-65. Available online: https: / / www.jschild.med-all.net/Contents/private/cx3child/2020/007901/008/0055-0065.pdf (accessed on 11 October 2021).

10. Chen, G.; Dunn Galvin, A.; Campbell, D.E. Impact of COVID-19 pandemic on quality of life for children and adolescents with food allergy. Clin. Exp. Allergy 2021. [CrossRef] [PubMed]

11. Searing, D.A.; Dutmer, C.M.; Fleischer, D.M.; Shaker, M.S.; Oppenheimer, J.; Grayson, M.H.; Stukus, D.; Hartog, N.; Hsieh, E.W.Y.; Rider, N.L.; et al. A phased approach to resuming suspended allergy/immunology clinical services. J. Allergy Clin. Immunol. Pract. 2020, 8, 2125-2134. [CrossRef] [PubMed]

12. D'Auria, E.; Anania, C.; Cuomo, B.; Decimo, F.; Indirli, G.C.; Mastrorilli, V.; Santoro, A.; Sartorio, M.U.A.; Veronelli, E.; Caffarelli, C.; et al. COVID-19 and food allergy in children. Acta Biomed. 2020, 91, 204-206. [CrossRef] [PubMed]

13. Shaker, M.S.; Oppenheimer, J.; Grayson, M.; Stukus, D.; Hartog, N.; Hsieh, E.W.Y.; Rider, N.; Dutmer, C.M.; Vander Leek, T.K.; Kim, H.; et al. COVID-19: Pandemic contingency planning for the allergy and immunology clinic. J. Allergy Clin. Immunol. Pract. 2020, 8, 1477-1488.e5. [CrossRef] [PubMed]

14. Izquierdo-Domínguez, A.; Rojas-Lechuga, M.J.; Alobid, I. Management of allergic diseases during COVID-19 outbreak. Curr. Allergy Asthma Rep. 2021, 21, 8. [CrossRef] [PubMed]

15. Barni, S.; Giovannini, M.; Sarti, L.; Liccioli, G.; Biagioni, B.; Novembre, E.; Mori, F. Managing food allergy immunotherapy in children during the COVID-19 pandemic. Allergol. Immunopathol. 2021, 49, 150-152. [CrossRef] [PubMed] 
16. Greenhawt, M.; Shaker, M.; Stukus, D.R.; Fleischer, D.M.; Hourihane, J.; Tang, M.L.K.; Abrams, E.M.; Wang, J.; Bingemann, T.A.; Chan, E.S.; et al. Managing food allergy in schools during the COVID-19 pandemic. J. Allergy Clin. Immunol. Pract. 2020, 8, 2845-2850. [CrossRef] [PubMed]

17. Brar, K.K.; Harizaj, A.; Nowak-Wegrzyn, A. Management of anaphylaxis during the SARS-CoV-2 pandemic. Curr. Treat. Opt. Allergy 2021, 8, 88-96. [CrossRef]

18. Ozturk, A.B.; Baççığlu, A.; Soyer, O.; Civelek, E.; Şekerel, B.E.; Bavbek, S. Change in allergy practice during the COVID-19 pandemic. Int. Arch. Allergy Immunol. 2021, 182, 49-52. [CrossRef] [PubMed]

19. Krishna, M.T.; Beck, S.; Gribbin, N.; Nasser, S.; Turner, P.J.; Hambleton, S.; Sargur, R.; Whyte, A.; Bethune, C. The impact of COVID-19 pandemic on adult and pediatric allergy \& immunology services in the UK National Health Service. J. Allergy Clin. Immunol. Pract. 2021, 9, 709-722.e2. [CrossRef] [PubMed]

20. Nakazato, K.; Shimonaka, Y. The Japanese State-trait anxiety inventory: Age and sex differences. Percept. Mot. Ski. 1989, 69, 611-617. [CrossRef] [PubMed]

21. Papadopoulos, N.G.; Custovic, A.; Deschildre, A.; Mathioudakis, A.G.; Phipatanakul, W.; Wong, G.; Xepapadaki, P.; Agache, I.; Bacharier, L.; Bonini, M.; et al. Impact of COVID-19 on Pediatric Asthma: Practice Adjustments and Disease Burden. J. Allergy Clin. Immunol. Pract. 2020, 8, 2592-2599.e3. [CrossRef] [PubMed]

22. Tagami, K.; Sugiura, S.; Kobayashi, T.; Kawabe, T. A survey of emergency room visits of children with immediate food allergy during the coronavirus disease 2019 pandemic. Jpn. J. Pediatric Allergy Clin. Immunol. 2021, 35, 117-120. [CrossRef] 